\title{
Interdisciplinary aspects in organizing the Music Education lessons
}

\author{
ALEXANDRA-IOANA HOMONE, PhD Student \\ "Gheorghe Dima" National Academy of Music Cluj-Napoca \\ ROMANIA*
}

\begin{abstract}
The $21^{\text {st }}$ century brings many changes in the education system regarding the teaching-learning-assessment process. Moving the importance from knowledge to the skills gained by the student requires the rethinking of the didactic strategies, and interdisciplinarity wins more and more in front of the monodisciplinary activities. On the other hand, the presence of technology in the traditional space dedicated to learning has led to the creation of new contexts in which the students can acquire new knowledge, develop skills trained in different subjects. The special circumstances in which school has been in 2020 put the importance of technology on a high level in the teaching-learning-assessment process. Online education has brought new challenges, which have added personal concerns for interactive and interdisciplinary activities. Therefore, our paper presents several ways of approaching interdisciplinarity in Music Education lessons, providing solutions validated by the results obtained in activities with students.
\end{abstract}

Keywords: interdisciplinary, music, applications, collaboration.

\section{Introduction}

2020 was the year characterized by a great challenge for all teachers, because everyone had to adapt to new ways of online, synchronous or group activities. A good professional training proved to be insufficient in the absence of digital skills, knowledge of various educational platforms and programs. Confronting the unknown with situations that seemed ephemeral, turned quite quickly, for many teachers, into an assiduous concern for rethinking the way we work with students, for developing strategies different from what is currently applied. Music Education teachers also faced such problems, because the subject is a discipline that, due to its specificity, involves face-to-face collaboration.

In fact, the transition of online teaching was a turning point for education, regardless of its nature, because the most important element, the relationship between teacher and student, was affected by the lack of direct contact, at present being mediated through educational platforms and programs. The difficulties that have arisen are numerous; we mention among them the insufficient level of digital skills, the lack of necessary logistics

\footnotetext{
*alexandra.jurje@amgd.ro
} 
(laptops, internet connection), the class management tools together with the suitable ones for teaching-learning-assessment activities, but also a limited involvement and the absence of motivation, both from teachers and the educated (Botnariuc, Cucoș, Glava, Iancu, Ilie, Istrate, et al., 2020, p. 12).

However, many teachers have managed to reinvent themselves, to find the proper creative resources so as to capture the attention of "prisoner" (sometimes bored) students in front of the screens during the daily school programe. In some of the cases, the solution found was the active-participatory collaboration between the teachers, who oriented themselves towards interdisciplinary activities, less capitalized on in previous didactic activities. The need to develop digital skills has led to learning applications and how to work on various platforms. In the end, many teachers discovered new ways of doing learning activities, different from what they had done before, but effective and appreciated by students.

\section{Interdisciplinarity in the curricular documents}

Anchored in the social realities of the contemporary era, the Romanian educational system of the $21^{\text {st }}$ century promoted through its curricular documents a new mentality on the teaching-learning-evaluation process, focused on the student and the skills that he must acquire during it. In case of the Music Education class, the teaching activity needs an interaction with the personal activity of each one, starting from what can be found in the student's living environment, in order to reach the formation of some musical skills and abilities. To do these things it is necessary that the way in which the teacher thinks be interdisciplinary. At the same time, the important elements in the realization of the contents are represented by the system of principles and criteria that the teacher must take into account when preparing his lessons. One of these points is the fulfilling of the relation of cooperation-collaboration of the scientific subject on the interdisciplinary, pluridisciplinary and transdisciplinary levels (Bontaș, 2008, p. 112). The trio made by these terms starts from the word discipline, associated with various prefixes, which contribute to offering a multitude of meanings that all target the student as the center of the educational system.

Interdisciplinarity is defined as the coordination between two disciplines, at a superiour level, their meanings interact and complete each other in order to reach an integrated common content (Bontaş, 2008, p. 112).

The documents underlying the educational system present interdisciplinarity aspects, so that students can correlate scientific information from different sources. In the case of Music Education, a discipline attended in the middle school cycle, in mainstream schools the school curriculum proposes the integration of interdisciplinarity elements starting from the $5^{\text {th }}$ grade. This is targeted even by the content area called Heteronomic and Interdisciplinary 
Cultural Aspects (Programa școlară, 2017, p. 6). It aims to relate music to the socio-cultural and historical-geographical context of the time, respectively to identify the elements of syncretism and the use of the Internet.

Since the legal framework exists and gives us the opportunity to create connections and make lessons more creative, there is a need for openness and collaboration from teaches. Scientific contents can be connected to each other, as long as teachers are sufficiently prepared to pass this information on to students. It's a challenge to create interdisciplinary content, but it's a joy to see how students react differently when they work in different ways with new content.

\section{Examples of own interdisciplinary approaches in Music Education lessons}

In the case of the didactic activity carried out online in the Music Education classes, the approach was totally changed because the practical element, the most important one, couldn't be realized as it was usually done in class. The reason is that there isn't a platform or program that allows a number of people to play or sing simultaneously in real time, with opened microphones, as it usually happens under normal conditions in the classroom. Therefore, like other music teachers, I had to reevaluate my teaching-learning methods and find ways to keep students' interest alive.

The elaboration of a new classroom work strategy also included the interdisciplinary approach for some topics. The steps followed in the didactic planning were: discussions with teachers from other disciplines to achieve the concordance between the calendar plannification of each party involved; discussion with teachers on the topict to be addressed in both subjects; teachers' working meetings to verify and valide the information collected; debating proposals for activities that can be implemented in the classroom and finally, their actual application with the students, in online lessons.

The preparation of interdisciplinary activities required time and ingenuity to escalate the obstacles along the way. The first problem identified in the preparation of these lessons was related to the calendar planning, made by each teacher as early as the beginning of the school year and difficult to modify subsequently. Once the opportune moment was established to carry out the interdisciplinary activities, each of the teachers had a short period of time (several days) to prepare the material that would be presented in the working meeting, respectively to identify the interest activities that can be implemented for the approached subject. During the working meeting, the scientific information to be presented to the students was verified and validated. The purpose of the practical activities was to develop musical skills and abilities starting from the knowledge from other fields, which the students have acquired over time and from the lesson from the other discipline involved. 
Also, through the practical activity of the Music Education class, we observed whether the musical meaning can be easily identified by certain methods and teaching aids, used for online education. The essential element of this approach was the collaboration of at least two teachers and the observance of the work plan, so that the content offered to students was mastered by them in an interactive manner. The implementation part will be presented in detail below for different interdisciplinary combinations that were made between March and December, 2020.

\subsection{Music and History}

We will describe our examples starting from the connection between music and history. Following all the stages of preparing a lesson, in the implementation one, we debated a lesson that approached as subject the Musical Chronology, in the $9^{\text {th }}$ grade. The main problem was that the duration of the Music Education class is fifty minutes, once every two weeks, while the History classes take place weekly. Another aspect that appeared during the planning stage is related to the contents mentioned in the school curriculum, which the students had to learn in $9^{\text {th }}$ grade, totally different in the two subjects. By mutual agreement, it was decided to hold an hour in both history and music where the eras were classified, together with a brief characterization of them. First, the chronology was made in the history class because it's easy to operate with general knowledge, and later, starting from the knowledge assimilated to this discipline, the musical eras were established. The main purpose that we had in mind was to identify the common elements (more precisely the periods) regarding the name of the era, because we know that the musical ones didn't take place simultaneously with certain historical periods.

The teaching strategy implied the following methods: learning by discovery, heuristic conversation and music listening. Each era was introduced through a set of questions related to the historical information that students had, and later, the era was customized with the help of musical audition, in order to discover some defining characteristics of the period. The feedback from the students was impressive because they weren't aware that music was among the last arts to develop. At the level of teaching aids used, the development of the activity in the online environment allowed a greater diversity. We made a film especially for this lesson presenting the historical and musical epochs, in which general data were included, as well as auditory elements specific to the mentioned periods. In addition to this audio-visual element, a worksheet with multiple choice items and a game in the form of "hangman" was created as an application. 


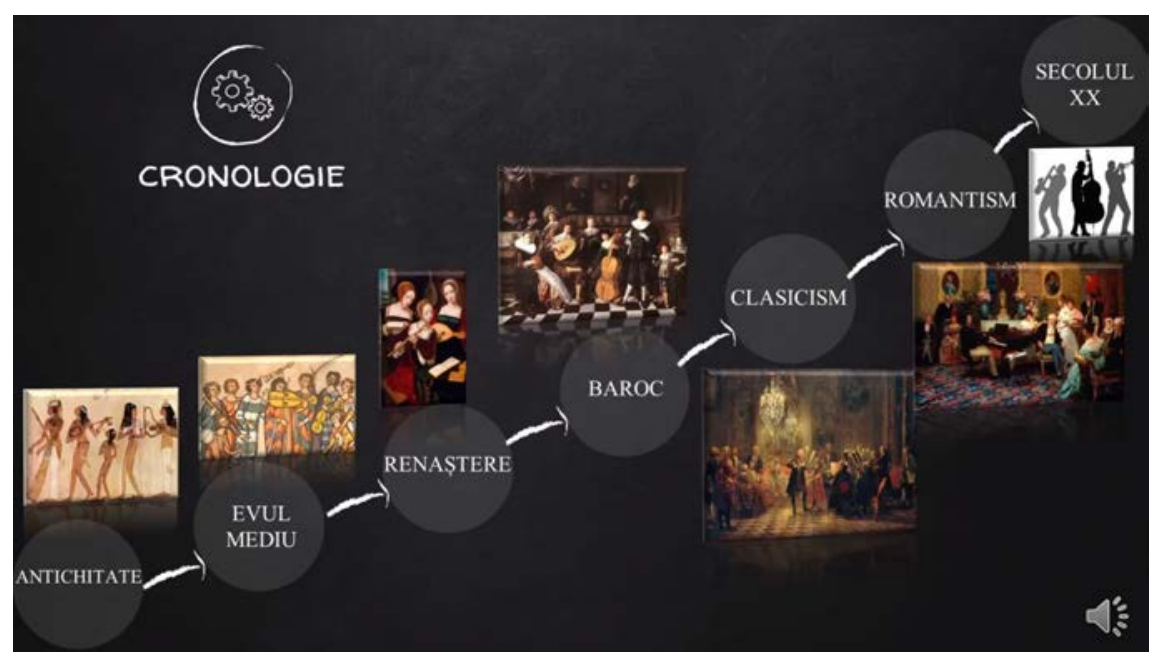

Fig. 1 Capture from the presentation movie dedicated to the Musical Chronology lesson

\subsection{Music and Romanian language and literature}

A topic in the school curriculum for Music Education, which is usually done in an interdisciplinary form, is that of the Doina and Balada lesson. These two gernres of folklore were approched from a literary and musical perspective. The challenging aspect was the one regarding that in Romanian Language and Literature the content is studied in the $6^{\text {th }}$ grade, while in music it's done only in the $7^{\text {th }}$ grade. Starting from the communication of the teachers involved, we established that the music lesson should be thought out starting from what was previously discussed in literature. In the planning meetings, the teacher with whom I did the topics in an interdisciplinary way presented the lesson material, how the explanations were made to the students and what the applications look like, so that the students could differentiate between the two genres. In the opening of the music class, I made a Venn Diagram to see what the similarities are and the different characteristics between the two literary genres. Even though the beginning lasted a little longer than I thought, later, due to the musical examples listened to, everything started to clarify, and the students discovered similarities and differences for the subjects from the musical perspective. The work tasks formulated before hearing the examples were easily solved; the students identified the theme based on the lyrics and, following the form and musical characteristics of the songs listened to, it was easy for the students to mention in which category they can place them. The students actively participated in the class, being engaged in the form of an audition-based musical genre identification game. 


\subsection{Music and Maths}

For the $5^{\text {th }}$ grade, where elements of musical language are mainly studied, I collaborated with the mathematics teacher because I turned my attention especially to the rhythmic notions and the way they are marked, considering that music is a fun form of mathematics. The combination of durations in the measures involves mathematical operations that students learned in primary school. However, learning durations and making combinations of them to varying degrees puts students in difficulty.

The planned lesson had as principal purpose recapitulating the rhythmic values in the form of a game, which had as main task for the students the making of a collective "pizza" whose ingredients were precisely the rhythmic values. The countertop was represented by the whole note, then the "pizza" was divided in turn in several pieces (halves, quarters, etc.) with the help of students, who had to add a new "ingredient", then transformed into a new duration corresponding to the division made. In addition to logicalmathematical intelligence, the interpersonal one was activated because students had to cooperate and collaborate as a team regarding the ingredients that had to be placed on the pizza, therefore the culinary skills were also formed, this part being fun for students. After finishing the game, which had the role of capturing the students' attention and, at the same time, of updating the knowledge about rhythmic values in a different form than usual, a diagram with their synthesis was noted on the board.

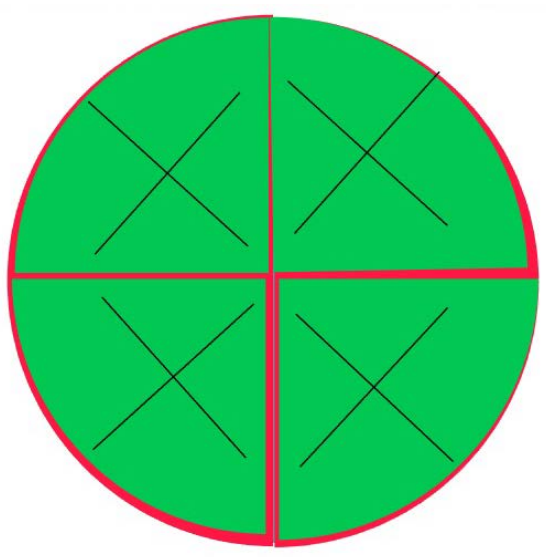

Fig. 2 Collective Pizza - layers of whole note, eights and sixteenths

Following the lesson, with the help of a worksheet, music took the form of mathematics. There were three different types of exercises through which students better mastered their theoretical notions. In the first, students had to use mathematical operations to find equality by noting a number, starting from 
knowing the value of written musical signs. The second exercise used only one rhythmic value next to which the students had to mention another one to give the result noted at the end of the exercise. The last exercise indicated only the result, leaving open the possibility for students to make their own rhythmic combination, by involving at least two rhythmic values.

Of course, the practical element was present in every hour of music through rhythmic exercises that included elements of body percussion. This type of exercise, through which rhythmic habits were formed, became routine, being the warm-up part from the beginning of music classes.

\subsection{Music and ICT}

Another important combination which has a huge impact, especially in the context of 2020, was the link between ICT (Information and Communication Technology) and music. First of all, before the meeting with the other teacher regarding what we can do together, it was necessary to improve my digital skills and discover what new types of applications I can integrate in an hour apart from simply using the Microsoft Office Suite or the music editing programs. ITC, together with a lot of platforms and programs, comes to the aid of the music teacher and supports the learning of musical content by students through programs and activities that can be done, thus developing students' digital skills and musical skills that they can acquire (Philpott, 2005, p. 116).

One of the most used applications was the Google Chrome extension called Chrome Music Lab. With the help of the app there were made reinterpretations of some songs that the students knew in form of melodic dictations - Melody Maker, melodic, rhythmic or melodic-rhythmic creation exercises were done, where some concrete tasks were given such as the use of certain musical notes, respectively the modification of the tempo - Song Maker or Rhythm; and, last but not least, the artistic side was involved by creating musical drawings where students could draw a landscape or some geometrical shapes, which were eventually converted into musical sound, resulting in a melody - Kandinsky. This application can be used not only for a specific topic, but can be easily integrated into as many topics as possible, giving students the opportunity to develop their creative spirit. The collaboration with the ICT teacher was regarding the decoding of the technical language, if there were problems in the connection and in the use of the application. The students were interested and started using what they found in Google's music lab, not only in music, but also in other disciplines. 


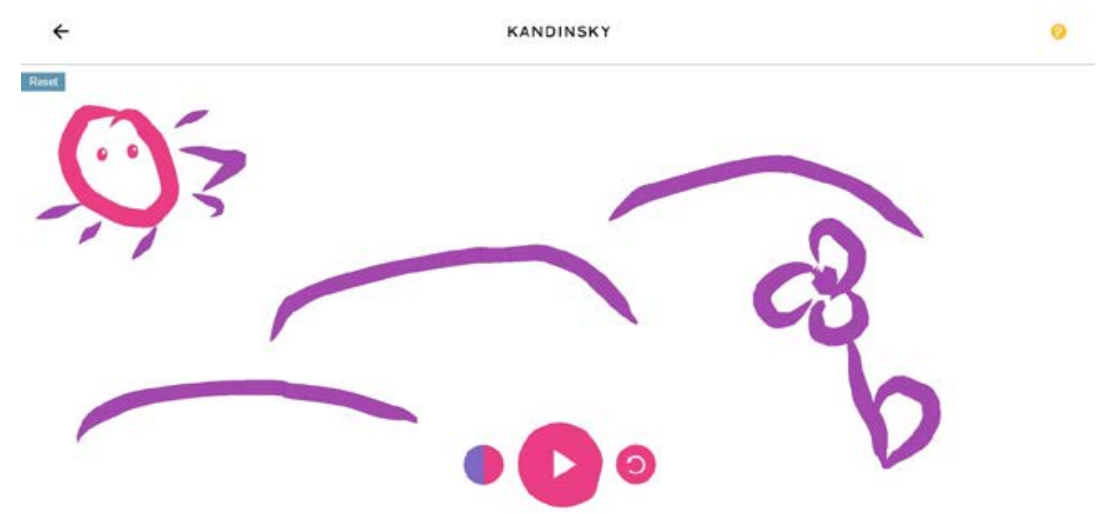

Fig. 3 Musical drawing made in Kandinsky

\subsection{Music, Physical education and Career guidance}

In 2019/2020, I had the opportunity, in the high school where I teach, to lay the foundations of an optional discipline called Music, dance and good manners in society. The aim was for students in the $11^{\text {th }}$ grade (specialization in Philology) to develop their musical taste and aesthetic values starting from what they observe in society; at the same time, we aimed to make them aware of how they may be affected by the decisions they make. The content debated over a year took into account the development of current musical genres, of great interest to students, dances, as well as the practical realization of movements, namely educating young people on how to behave in society. Interdisciplinarity was a combination of disciplines such as Physical education, Counseling and career guidance (form master class), Music education, etc.

The element that involved body movement wasn't only based on rhythmic exercises, but also included learning dance styles. In addition to these elements of movement, the way we behave with each other was also targeted, this contributing to the cohesion of the relationship between the students of the class and to the well-grounded knowledge of each student's personality. Theatrical elements were also added, each student being able to discover his own personality through a series of diction exercises, role interpretation and debates on various topics. Finally, we set out to do an artistic event, in which to present everything that was learned during the year. Being something new, interactive and where the knowledge didn't follow theoretical resources, but imply rather practical elements, the students quickly adapted to what they had to do, being open to any new challenges.

Regarding the organization of this new optional discipline, I collaborated with the leading teacher of the class - who provided me with important data about the students in the class - and with the physical education teacher, with whose help I had the opportunity to do the class in another space than the music room. The assessment method used online was in written form with the 
aim of verifying students' ability to apply knowledge in other contexts than those known in the teaching activity (Dulamă, 2020, p. 61). The questionnaire consisted of short-answer items, free in form and content.

\section{Conclusions}

Creating lessons of Music Education is a challenge for the teacher who works in mainstream schools in this century of technology. In order to captivate students, often more oriented towards science, mathematics or other fields, those who teach this subject must be creative and have varied skills, in addition to musical talent, and the interdisciplinary approach can be a viable solution.

The move of the educational process over to the virtual space required a rapid adaptation and rethinking of teaching strategies so that the educational process retains as much as possible the characteristic of what is commonly practiced in a classroom. There is no recipe for the perfect lesson, but rather through the personality of the teacher, the way he interacts with students and his vision of the discipline, unprecedented things can be done and activities to learn certain content can take a new form, attractive to students.

The interdisciplinary lessons in the subject of Music Education that were done online were a continuation of the approach of previous years to achieve student-centered learning emphasised by adopting an interactive model. We considered that the interdisciplinary approach must be seen from the perspective of the student, not only from that of the teacher, having as a basic pillar the personality and skill of the educated because they are addressed first of all. Why is it important to carry out interdisciplinary activities? Because they contribute to the student's development and help him to holistically perceive the surrounding reality.

The success of the activities I designed depended on a good knowledge of the classes of students I worked with. I tried to adapt to the personalities of the students and their interests in order to transform the music class from the banal conversation on theoretical issues and learning a song, into an hour that would help them discover the musical universe by using their own skills and satisfying their perceived needs.

The preparation of interdisciplinary activities highlighted the importance of the collaboration of teachers for a better knowledge of their students, but also communication, as a key point of the educational process.

Digital skills are one of the priorities of the $21^{\text {st }}$ century and represent a challenge for each of us, that we must face through continuous information. The activities carried out demonstrated how important it's for our teaching strategies to include technology, to capitalize on the opportunities offered by various educational platforms in diversifying learning tasks, for communicating with students, developing critical thinking and creative 
expression. The integration of technology with musical activities has allowed students to work at their own pace and improve their learning outcomes, behaviour and attitude towards the discipline.

The interdisciplinary approach helped to form the general and specific competencies of the discipline, but also led to the development of behavioral skills. It provided students with motivation, aroused enthusiasm, improved active class attendance, and increased the self-confidence of students who were unwilling to sing or play during class hours. Therefore, we can conclude that a well-planned teaching strategy, which combines the specific activities of Music Education - vocal singing, music listening and instrumental practice - with technology and the interdisciplinary approach to education is the safest way to optimize lessons, regardless of the school cycle we work with.

\section{References}

Bontaş, I. (2008). Tratat de pedagogie, ed. a VI-a [Pedagogy Treatise, $6^{\text {th }}$ ed.]. București: Editura All.

Botnariuc, P. \& Cucoș, C. \& Glava, C. et al. (2020). Școala online pentru inovarea educației - Raport de cercetare evaluativă [Online School for Educational Innovation]. București: Editura Universităţii din București.

Dulamă, M. E. (2020). De la teorie spre practică în evaluarea on-line [From theory to practice in online assessment]. Acta Didactica, 20. Cluj-Napoca: Presa Universitară Clujeană.

Philpott, Ch. (2005). Learning to Teach Music in the Secondary School - A Companion to School Experience. London: Taylor \& Francis E-Library.

* * * Programa școlară pentru disciplina EDUCAȚIE MZICALĂ. Clasele a V-a - a VIII-a. Retrieved from http:/programe.ise.ro/Portals/1/Curriculum/2017-progr/63Educatie\%20muzicala.pdf 